\title{
Collapse analysis of reinforced and unreinforced adobe masonry structures under earthquake actions - case study: Bam Citadel
}

\author{
T. Bakeer \& W. Jäger \\ Structural Design, Dresden University of Technology, Germany
}

\begin{abstract}
Bam Citadel, the largest adobe masonry building in the world, collapsed under the earthquake of 2003. From a wide range of structures in Bam Citadel two rooms were selected for collapse analysis. A combined FEM/DEM method was used through explicit dynamic LS-DYNA software. A macro modelling strategy has been chosen for masonry modelling. Potential cracks were defined by the aid of CAD software for the whole geometry. Collapse analysis of the structure without reinforcement has been done in order to determine the weak points through the collapse sequence. The collapse of the unreinforced structure was used as a guide for reinforcement locations. Reinforcement trials by glass fiber bars with different locations and values have been tested to show the effect of reinforcement on the collapse behaviour. Finally, glass fiber reinforcement bars have been designed to prevent the collapse.
\end{abstract}

Keywords: adobe masonry, collapse analysis, macro modelling, combined FEM/DEM, explicit dynamic.

\section{Introduction}

Bam Citadel was the largest adobe building in the world, located in Bam, a city in Kerman province of southeastern Iran. It is listed by UNESCO as a part of the World Heritage Site "Bam and its Cultural Landscape". This enormous citadel was built some time before $500 \mathrm{BC}$ and remained in use until $1850 \mathrm{AD}$.

On December 26, 2003, the citadel was almost completely destroyed by a 6.5 Richter scale earthquake and more than $90 \%$ of the (sun-dried) adobe and 

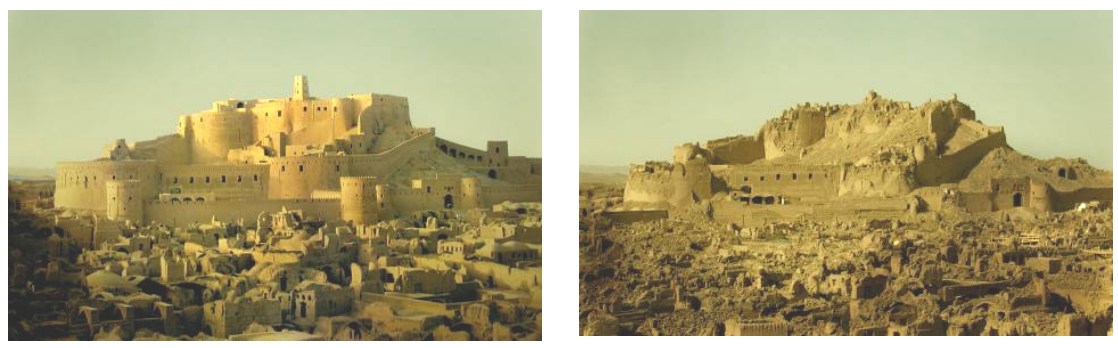

Figure 1: $\quad$ Bam before and after the earthquake.

masonry structures collapsed, leaving ruins with only a few remaining walls and piers, Figure 1.

From the wide range of structures in the Bam Citadel, the so-called Sistani's House was chosen as a pilot project and particularly the two rooms R0.11 and R0.12 in the northwest corner were selected for study, Figure 2.

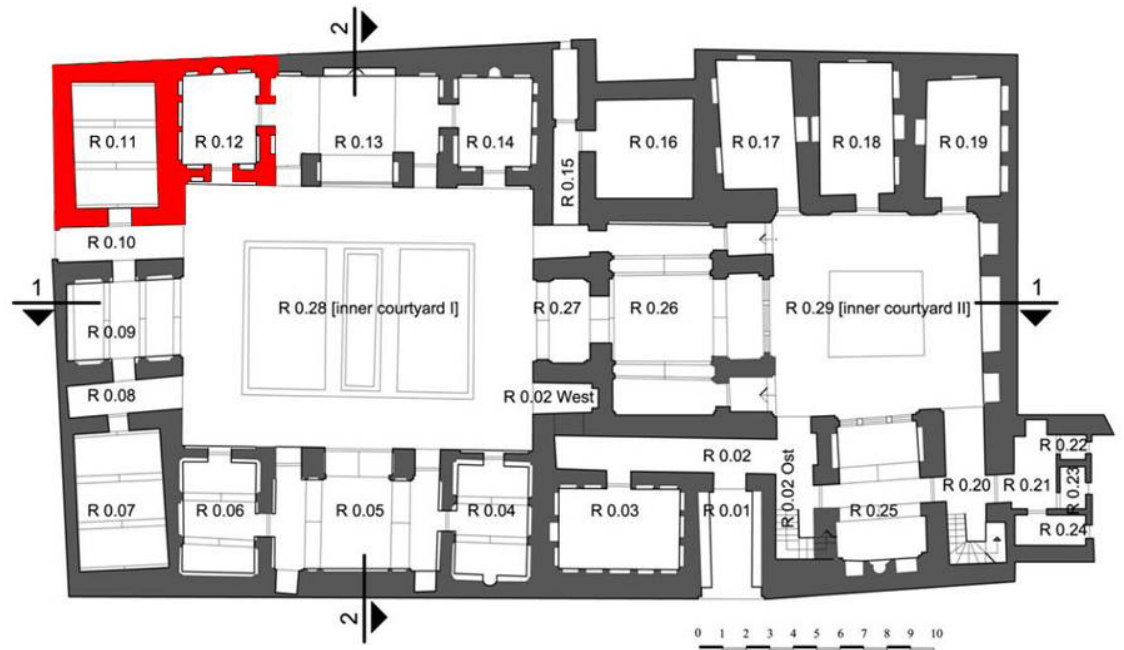

Figure 2: Ground plan of the Sistani's House, selected part for the pilot project marked in red.

The collapse analysis of Sistani's House under earthquake action will be accomplished. In addition strengthening cases will be discussed in the following sections.

\section{Methodology}

The simulation of earthquake actions on the structures and analyzing the collapse sequence are of high importance for investigating the weak points in the structure and for suggestions regarding strengthening measures. 
The increasing of stresses, the failure of material, the fracture, the fragmentations then the collapse and very complicated subsequent contactimpact and energy dissipation mechanisms lead to the final state of rest, which is often just a pile of rubble.

The relatively short duration and the high degree of nonlinearity associated with impacts on masonry during earthquake action meant that it was convenient to employ the general purpose non-linear explicit finite element software LS-DYNA for the modelling work. The use of an explicit solution strategy eliminates many of the numerical difficulties that arise by using implicit solvers [1].

A macro model has been chosen for modelling the structure to reduce the model size and calculation efforts. The combined finite-discrete element method (FEM/DEM) [7] was used to build the geometry. Potential cracks were defined on the splitting surfaces between discrete elements using a contact model.

\section{Modelling in LS-DYNA}

\subsection{Geometry modelling}

For simulating the collapse, the structure was divided into individual parts (discrete elements) using CAD tools. The size of the discrete elements has been chosen as an appropriate size to show the collapse under the failures of predefined potential cracks on the sliding surfaces, Figure 3.

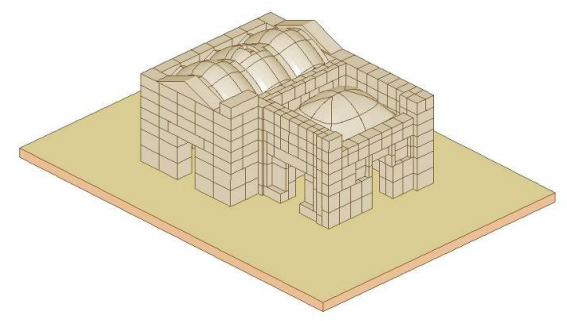

Figure 3: The geometry of the model.

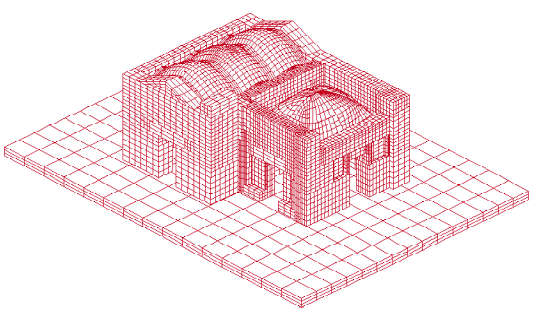

Figure 4: $\quad$ Finite element mesh.

The shape of the individual parts has been taken as regular as possible as for getting a simple finite element mesh, Figure 4.

The finite element mesh has been chosen to be as regular (eight node element) as possible so as to prevent the calculation problems and getting more accurate results.

\subsection{Material model}

Adobe masonry belongs to quasi-brittle material which fails due to a progression of internal crack growth. A MAT_SOIL_AND_FOAM constitutive model has 
been used to model adobe masonry material. This material model was mainly developed for cases of plan soils, foams, and concrete $[2,3,5,6]$.

\subsection{Contact model}

The LS-DYNA Contact model "Contact_Automatic_Surface_to_Surface _Tiebreak" has been used to model the failure surfaces in masonry $[1,3, \overline{5}, 6]$.

Tiebreak is active for nodes which are initially in contact. The slave nodes sticking permanently until they reach the failure criteria:

$$
\left(\frac{\left|\sigma_{n}\right|}{N F L S}\right)^{2}+\left(\frac{\left|\sigma_{s}\right|}{S F L S}\right)^{2} \geq 1
$$

where is NFLS normal failure stress, SFLS is shear failure stress.

After failure, this contact option behaves as a surface to surface contact with friction.

\subsection{Earthquake load}

The data for the accelerogram of Bam earthquake (05:26 on 26 December 2003 in Bam city, Kerman State, Iran) was taken from the records of the Bam accelerograph station record No.: 3168/02 [9]. The epicenter was located at 29.01 N and 58.26 E.

The total duration of the earthquake action was $66.55 \mathrm{sec}$, and had a magnitude of MW 6.5 (Ms 6.7 USGS). Peak accelerations for longitudinal, transversal, and vertical components were 778.2, 623.4, and 979.9 (gal), respectively, [4].

Because the direction of the accelerometer for the (L) component was N278E, this shows a vibration approximately in an east-west direction.

To reduce the calculation time, the calculations concerned in the period from $15.7 \mathrm{sec}$ to $30 \mathrm{sec}$ were the maximum acceleration values located in this period, Figure 5 .

\section{Collapse analysis of unreinforced structure}

The collapse sequence of the structure is presented in Figure 6, the adobe masonry structure almost collapsed completely under earthquake action. The vaults as well as the upper parts of the walls were destroyed completely. Just small parts of the walls still remain because they are fixed closely to the earth.

The tensile and shear strength at contact surfaces between discrete elements are taken into account in the LS-DYNA model, but this strength is not recognized during the collapse because it has small values in comparison with the friction coefficient.

The collapse simulation in LS-DYNA shows that collapse was initiated by overturning of discrete elements due to loss of bonding. It is the same failure mode presented in [4] for the adobe masonry buildings in Bam. The relatively high value friction coefficient $0.54 \sim 0.62$ causes this mode of collapse, and the 


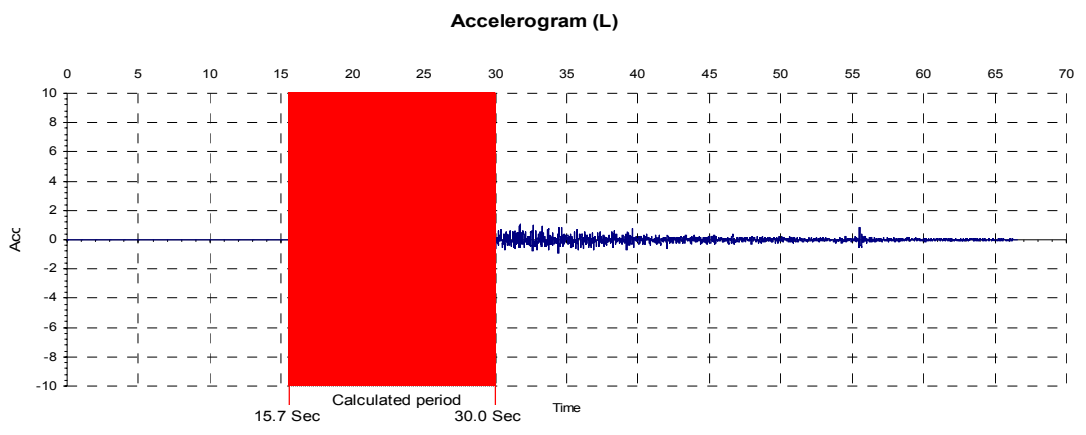

Accelerogram (T)

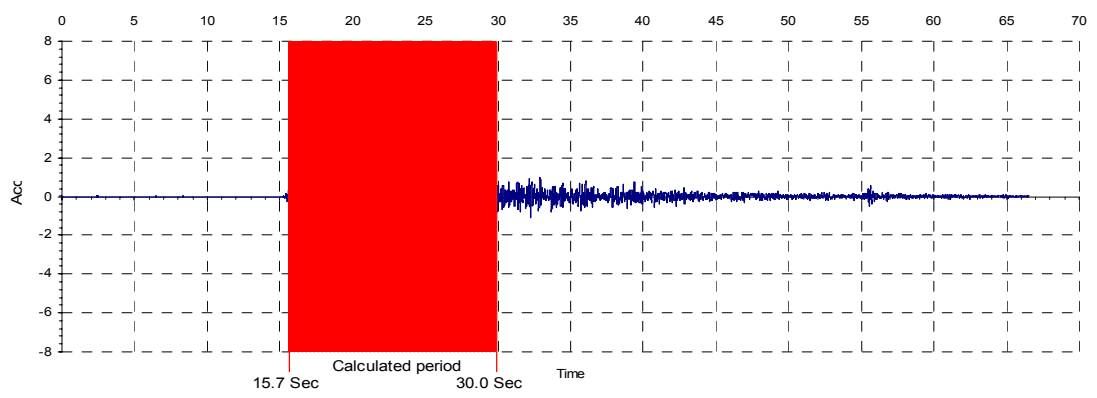

Accelerogram (V)

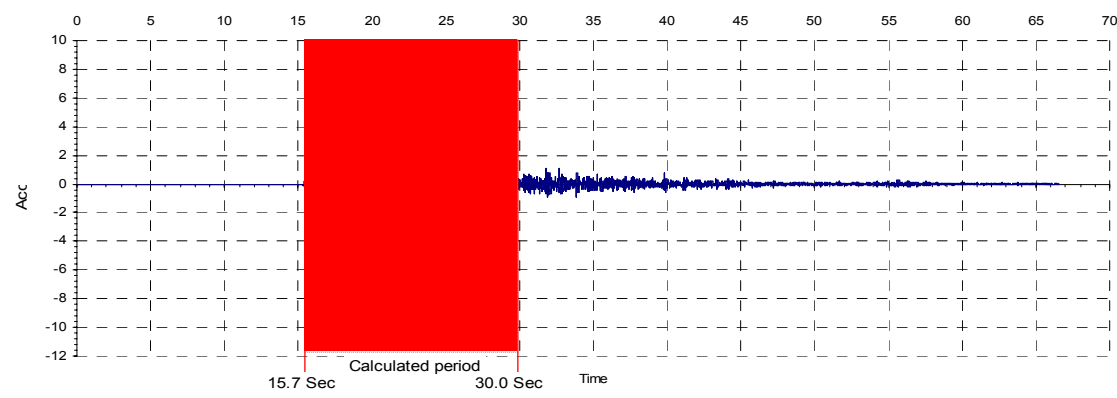

Figure 5: Records no. 3168/02 from Bam accelerograph station for the earthquake of 26/12/2003 [9].

improper bonding strength is one of the reasons which caused the complete collapse of almost all buildings in Bam.

\section{Suggestion of strengthening rely on collapse analysis}

Reinforcement measures by collapse analyses will be investigated in order to prevent the collapse of room 11. No reinforcement was added to room 12 for comparison purposes. Glass fiber bars with clay-cement grout will be used for reinforcement. 
The calculation results from collapse analysis for the unreinforced structure show the need to reinforce the room in the vertical and horizontal directions.

It is clear that the weak situation for the wall collapse is when forces are applied normal to its plan, but the combined work of the walls together by adding horizontal reinforcement cincturing the room will improve the stability of the rooms.

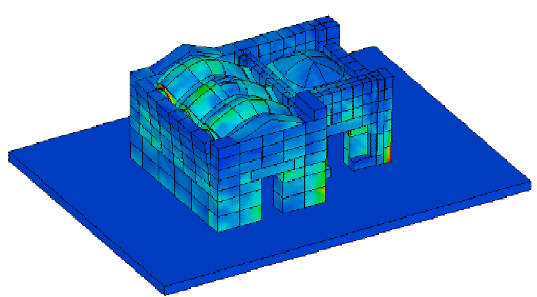

(1) $\mathrm{T}=17.37 \mathrm{sec}$

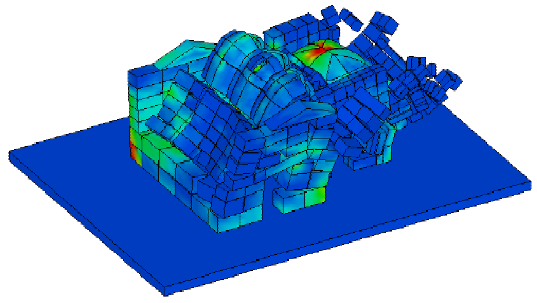

(3) $\mathrm{T}=17.94 \mathrm{sec}$

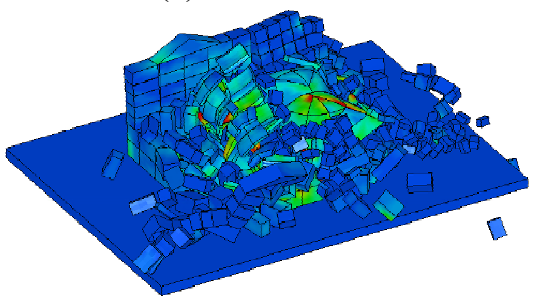

(5) $\mathrm{T}=18.80 \mathrm{sec}$

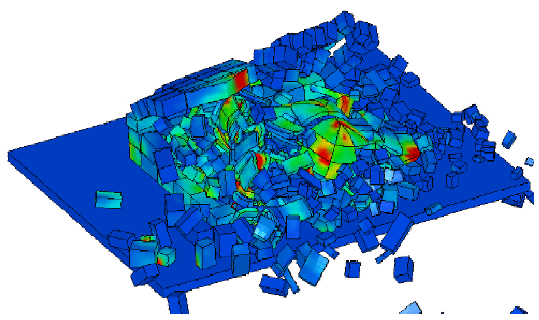

(7) $\mathrm{T}=19.66 \mathrm{sec}$

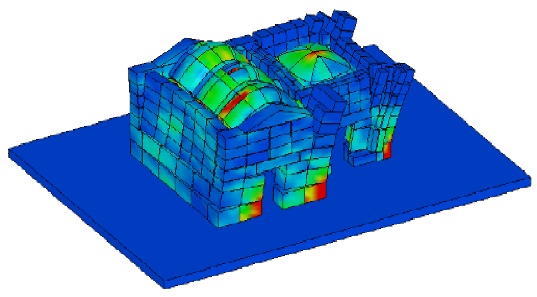

(2) $\mathrm{T}=17.65 \mathrm{sec}$

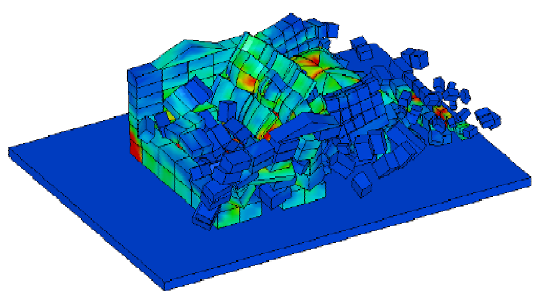

(4) $\mathrm{T}=18,32 \mathrm{sec}$

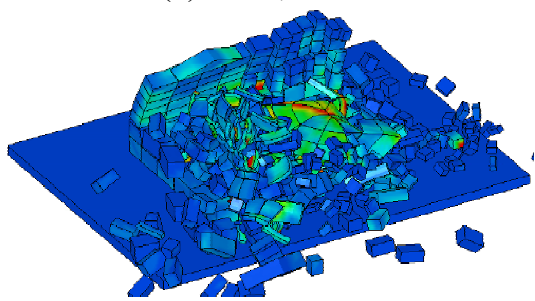

(6) $\mathrm{T}=19.28 \mathrm{sec}$

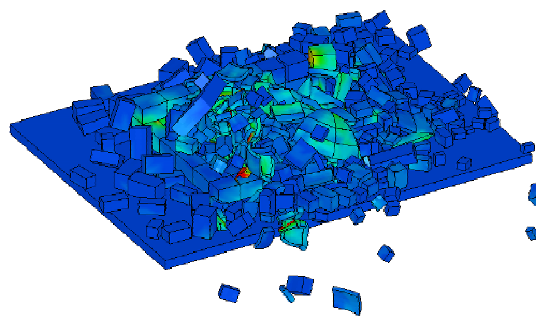

(8) $\mathrm{T}=21.47 \mathrm{sec}$

Figure 6: Collapse sequence of the house under earthquake action. 


\subsection{Modelling reinforcement bond failure in LS-DYNA}

A constrained spotweld was used in our study for modelling reinforcement bond failure. The spotweld is a rigid beam that connects the nodal points of the nodal pairs. It can be used to specify the normal force value at spotweld failure which represents in our case the pull-out force.

A spotweld is defined on a string of nodes which belong to each discrete element penetrated by the reinforcement rebar. The distance between the pair nodes tied by the spotweld is $0.5 \mathrm{~m}$. The maximum pull-out force for glass fiber bars should be taken for $0.5 \mathrm{~m}$ grout length.

\subsection{Reinforcement trials}

\subsubsection{Reinforcement trial no. 1}

Vertical and horizontal reinforcement added to the walls in the room are shown in Figure 7. A maximum bonding force of $10 \mathrm{KN}$ per $0.5 \mathrm{~m}$ has been taken in the calculation. In the final remains some walls still stand completely, others collapsed partially and the vault collapsed due to progressive collapse.

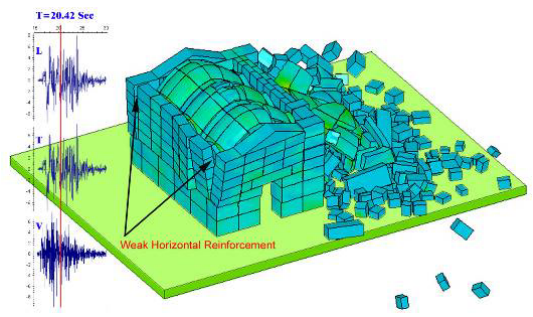

(1) $\mathrm{T}=20.42 \mathrm{sec}$

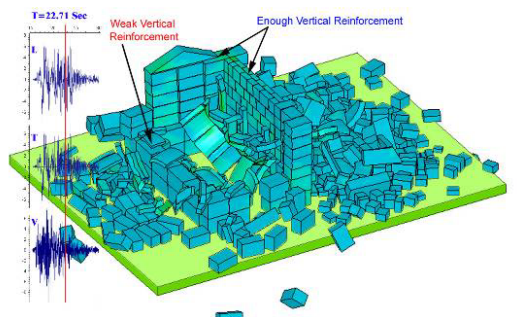

(4) $\mathrm{T}=22.71 \mathrm{sec}$

Figure 7: Collapse sequence of the structure under earthquake action, reinforcement trial no.1.

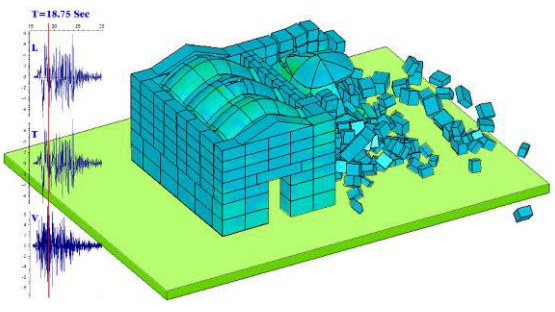

(1) $\mathrm{T}=18.75 \mathrm{sec}$

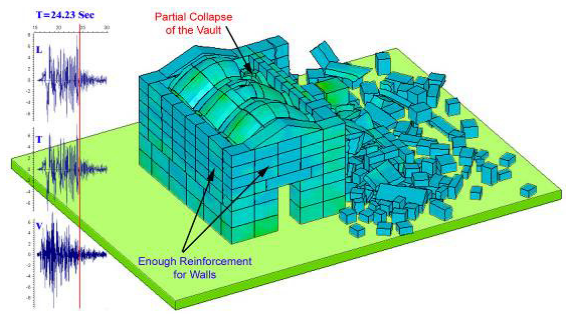

(4) $\mathrm{T}=24.23 \mathrm{sec}$

Figure 8: Collapse sequence of the structure under earthquake action, reinforcement trial no. 2 .

The reinforcement was enough for some walls, and it has to be increased for others. The making of new strong parts by reinforcement may change the last 
strong parts before reinforcement to weak parts after reinforcement. Therefore, symmetric reinforcement is preferred for seismic design.

It is clear from this trial that the horizontal reinforcement must be increased for the next trial.

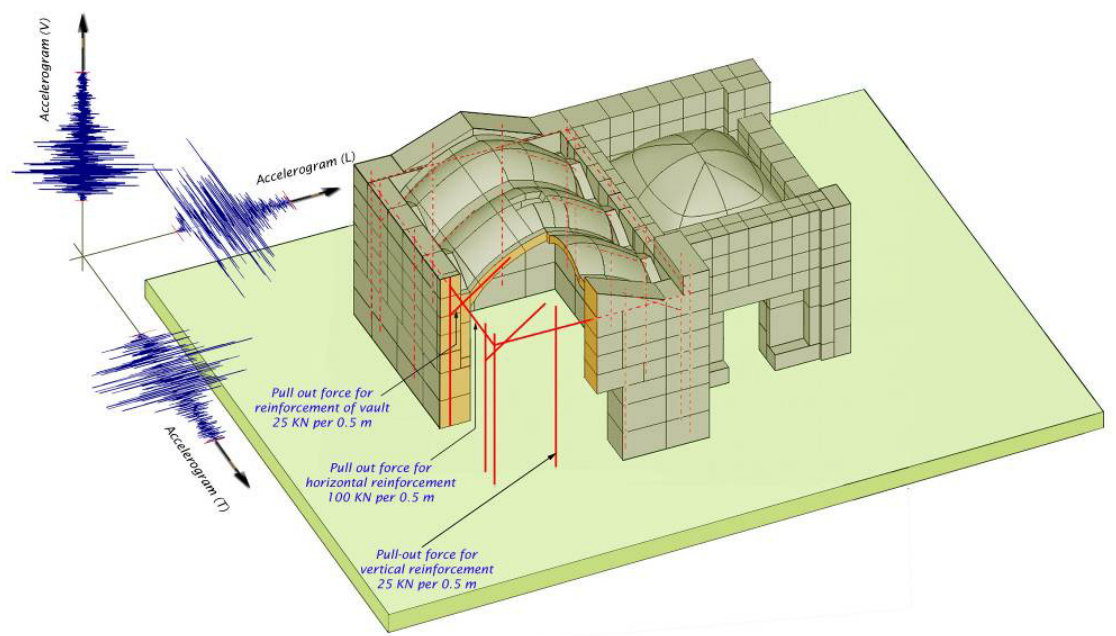

(a)

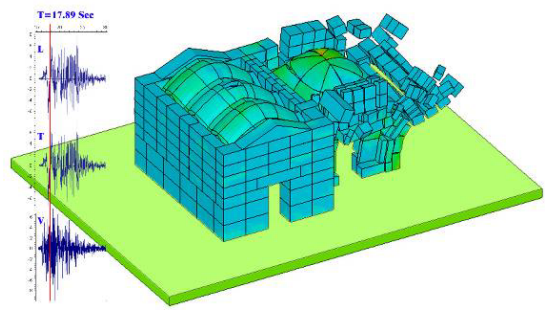

(1) $\mathrm{T}=17.89 \mathrm{sec}$

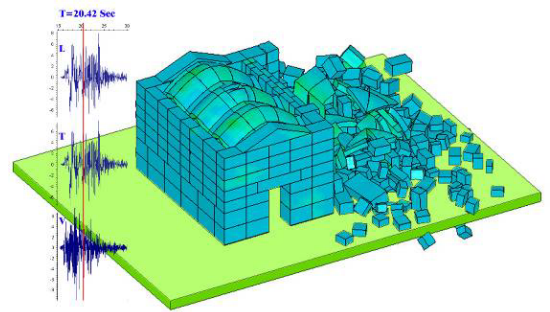

(3) $\mathrm{T}=20.42 \mathrm{sec}$

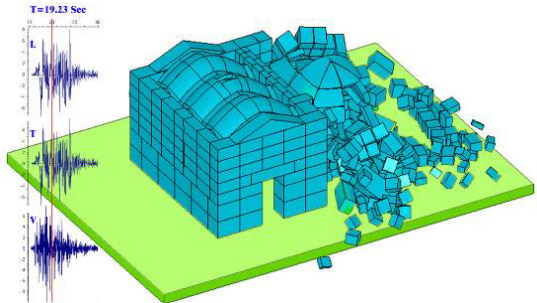

(2) $\mathrm{T}=19.23 \mathrm{sec}$

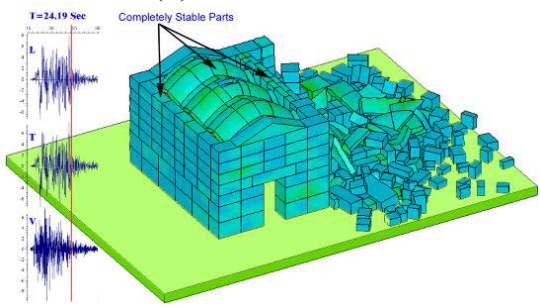

(4) $\mathrm{T}=24.19 \mathrm{sec}$

(b)

Figure 9: (a) View for the structure with vertical, horizontal and vault reinforcement, trial no.3. (b) Collapse sequence of the structure under earthquake action, reinforcement trial no.3. 


\subsubsection{Reinforcement trial no. 2}

The maximum bonding force for horizontal reinforcement increased to $100 \mathrm{KN}$ per $0.5 \mathrm{~m}$ and for vertical reinforcement to $25 \mathrm{KN}$ per $0.5 \mathrm{~m}$.

As a result, the walls of the room showed good stability, this stability stopped the progressive collapse to reach the vaults. The vault collapsed partially and showed big deformations, Figure 8 .

Thus, one task that should be done for the next step is to prevent the collapse in the vault.

\subsubsection{Reinforcement trial no. 3}

Reinforcement was added to the vaults with maximum bonding force $25 \mathrm{KN}$ per $0.5 \mathrm{~m}$, see Figure 9. This reinforcement helped the stabilization of the vault. As a final result, the room with this reinforcement trial has complete stable parts.

\subsection{Glass fiber reinforcement design}

Experimental tests have been done to investigate the pull-out failure force. The reinforcement bars were built $36 \mathrm{~cm}$ into the wall, which is the tested anchor length. For a standard glass fiber bar $\mathrm{d}=8 \mathrm{~mm}$ built into a drill hole $\mathrm{d}=30 \mathrm{~mm}$, the average maximum pull-out force for clay-cement grout was $9 \mathrm{KN}$. The average maximum pull-out force per $0.5 \mathrm{~m}=9 \times 0.5 / 0.36=12.5 \mathrm{KN}$.

By assuming that the reinforcement positions used in last models are the center of the glass fiber bars, the number of glass fiber bars can be calculated:

Number of bars for vertical reinforcement $=25 / 12.5=2$ bars. Number of bars for horizontal reinforcement $=100 / 12.5=8$ bars. Number of bars for Vault reinforcement $=25 / 12.5=2$ bars.

\section{Acknowledgements}

The authors would like to thank the German Team working in Bam who were instrumental to the successful completion of this work. The authors acknowledge Dipl.-Ing. David Wendland for constructing the geometry of the vaults and their discretization and Dipl.-Ing. Jörg Broun for his work on experimental tests. The authors are also grateful to Dr André Haufe from DYNAmore GmbH and Dr Matthew Gilbert from Sheffield University for their support in modelling using LS-DYNA.

\section{References}

[1] Beattie, G., Molyneaux, T.C.K., Gilbert, M., Hobbs, B., Burnett, S. \& Newton, P. \& Gration, D.A., Improving the impact resistance of masonry parapets. Proc. of the LS-DYNA Users Conference, LSTC: Paris, 2001.

[2] Davidson, J.S., Moradi, L. \& Dinan, R.J., Selection of a Material Model for Simulating Concrete Masonry Walls Subjected to Blast. Interim Technical Report: Air Force Research Laboratory in contribution with University of Alabama at Birmingham, Department of Civil and Environmental 
Engineering no. AFRL-ML-TY-TR-2006-4521. Air Force Research Laboratory. USA 2004.

[3] Hallquist, J.O., LS-DYNA Theory Manual, Livemore Software Technology Corporation: California, USA, 2005.

[4] Kiyono, J. \& Kalantari, A.: Collapse Mechanism of Adobe and Masonry Structures during the 2003 Iran Bam Earthquake. Bulletin of the Earthquake Research Institute, University of Tokyo, 79(3/4), pp. 157-161, 2004

[5] LSTC, LS-DYNA Keyword User's Manual, Livemore Software Technology Corporation: California, USA, 2003.

[6] LSTC, LS-DYNA User's Manual, Nonlinear Dynamic Analysis of Structures, Livemore Software Technology Corporation: California, USA, 1999.

[7] Munjiza, A., The Combined Finite-Discrete Element Method, John Wiley \& Sons: England, 2004.

[8] Taheri, S.M., Finite element modeling of adobe masonry buildings under earthquake loads and contribution of reinforcement in enhancement of load bearing capacity. MSc-Thesis, Dresden University of Technology, 2006. Dresden University of Technology: Dresden, Germany 2006

[9] Website of BHRC (Building and housing research center) in Iran, www.bhrc.ac.ir. 